\title{
ILUMINAR LA CAZA EN LA EDAD MEDIA: APROXIMACIÓN A LA ICONOGRAFÍA VENATORIA MEDIEVAL IBERORROMÁNICA *
}

\author{
José Manuel FradeJas RuEda \\ Universidad de Valladolid \\ josemanuel.fradejas@uva.es
}

El hombre desde sus más remotos orígenes se ha dedicado a la caza y ha practicado dos tipos básicos: la caza provisoria, para obtener alimento; y la caza defensiva, para protegerse de las alimañas que le rodeaban y acechaban. Con el paso del tiempo y el dominio de la agricultura y la domesticación, comenzó a practicar un nuevo tipo de caza, que básicamente es la que se ha mantenido hasta la actualidad: la caza lúdica ${ }^{1}$. Sin embargo, el ser humano antes de saber escribir, aprendió a pintar y, desde los más remotos tiempos, representó escenas de la vida cotidiana y del medio ambiente en el que vivió. Entre estas escenas destacan las de caza.

El arte rupestre, del que tenemos grandes muestran en la península Ibérica, tanto en la cornisa cantábrica (Altamira, San Román de Cándamo, Altxerri, etc.) como en el arco mediterráneo, ha legado palpitantes muestras de la preocupación del ser humano por representar la naturaleza y, en especial, los animales que cazaba y cómo eran sus acciones cinegéticas. A veces con representaciones humanas como las cacerías de cápridos, jabalíes o cérvidos en los abrigos mediterráneos de la cueva de la Araña (Valencia), la cueva Remigia o la Cova dels Cavalls (Castellón), la caza de aves en la Covatina

\footnotetext{
*Este trabajo, para bien o para mal, no se ha realizado bajo los auspicios de ningún proyecto subvencionado, pero toma sus datos y resultados de dos proyectos financiados, por el ministerio correspondiente en cada momento, entre los años 2006 y 2013 e identificados por las referencias HUM-2006-00932/FILO y FFI2010-15128 titulados Archivo Iberoamericano de Cetrería y cuyos resultados son accesibles en $<$ http://www.aic.uva.es $>$.

${ }^{1}$ José Manuel Fradejas Rueda, «Los libros de caza medievales y su interés para la historia natural», en Arbor (en prensa).
} 
del Tossalet del Mas de la Rambla o sencillamente animales heridos por las armas arrojadizas utilizadas -flechas o venablos- como se observa en el ciervo herido de San Román de Cándamo².

Las escenas venatorias son una constante a lo largo de la historia de la humanidad. Circunscribiéndonos a la cuenca mediterránea, a los territorios del mundo antiguo, tenemos representaciones de caza en las cámaras mortuorias de la princesa Itet (c. 2700 a. C.) o Nebamun (c. 1350 a. C.) en el Egipto faraónico. Los bajorrelieves asirios como los de la caza del león de Asurbanipal (siglo VII a. C.); las sencillas escenas de caza de liebres con galgos de algunas vasijas áticas del siglo vIII a. C. ${ }^{3}$ o etruscas del siglo vI a. C. ${ }^{4}$; las muchas representaciones de la caza del mítico jabalí Calidonio, como la del mosaico descubierto en San Pedro del Arroyo (Ávila) en 2006, sin duda una de las escenas venatorias más repetidas en la historia del arte europeo; o los mosaicos grecorromanos de la antigüedad tardía como el de la villa de Kélibia (Túnez) que refleja algunas de las técnicas venatorias utilizadas por los romanos al final del imperio ${ }^{5}$ que representa (de arriba abajo, y de izquierda a derecha): 1) caza de liebres a caballo; 2) caza del jabalí con redes; 3 ) caza de cetrería; 4) caza de aves con liga; 5) caza de perdices con "bueyes" 6

Con el transcurrir del tiempo, la caza, en especial la lúdica, que adquirirá un componente educativo, comienza a codificarse y a producir una literatura técnica que se inicia con el Cynegetico de Jenofonte en el siglo IV a. C., en el que se describe la caza de la liebre a pie y el enfrentamiento con el jabalí con una pica en la mano. La tradición grecorromana es breve y parca, pues a Jenofonte le siguen cuatro obras, todas bajo el mismo título: Cynegetica; dos escritas en Grecia debidas a Arriano (s. II d. C.) y Opiano de Apamea (s. III d.

${ }^{2}$ J. Casariego, La caza en el arte español, Madrid, Viso, 1982; Norberto Mesado Oliver, «Las pinturas rupestres de la Covatina del Tossalet del Mas de la Rambla», Lvcentvm 7-8 (1988): 35-56; Elisa Sarriá Boscovich, «Las pinturas rupestres de Cova Remigia (Ares del Maestre, Castellón)», en Lvcentvm, 7-8 (1988), pp. 7-33.

${ }^{3}$ J. Anderson, Hunting in the ancient world, Berkeley, University of California Press, 1985, p. 32, fig. 12.

${ }^{4}$ Ibid., pp. 40-41, fig. 17.

${ }^{5}$ Michèle Blanchard-Lemée et al., Sols de l'Afrique romaine: mosä̈ques de Tunisie, Paris, Imprimérie nationale Éditions, 1995, fig. 129.

${ }^{6}$ En el mosaico se utiliza un caballo, pero dentro de la tradición literaria española es más conocida por el buey de caza y su aparición en Celestina; pasaje que dio lugar a una serie de artículos: Dorothy Sherman Severin, «"El Falso Boezuelo", or the Partridge and the Pantomime Ox», en Celestinesca, 4:1 (1980), pp. 31-34; José Manuel Fradejas Rueda, «El "boezuelo", el "buey de caza" y el "cabestrillo"», en Celestinesca, 20:1 (1996), pp. 155-70; José Fradejas Lebrero, «Cazar aves con lumbre (más antiguo aún)», en Celestinesca, 18:1 (1994), pp. 75-78; E. Michael Gerli, «A propos the pantomime ox, sexual innuendo, and fuddled partridges: yet more on Pármeno's remark», en Celestinesca, 12:2 (1988), pp. 55-60; Nicasio Salvador Miguel, «Otros bueyes que cazan perdices», en Medievalismo: Boletín de la Sociedad Española de Estudios Medievales, 3 (1993), pp: 59-68. 
C.), y otras dos en Roma: los poemas de Gratio (s. I a. C. - d. C.) y Nemesiano (s. III d. C).

A la luz de la paupérrima producción del mundo clásico y su nula influencia posterior, se puede establecer que el libro de caza es un tipo de literatura didáctica y práctica de creación y desarrollo totalmente medieval. Entre los siglos $\mathrm{x}$ y $\mathrm{xV}$ se escriben un amplio catálogo de obras relativas a la caza o a sus auxiliares -cuadrúpedos y aves de presa- destinadas principalmente a un público que la practica ${ }^{7}$, pero que se limita a dos tipos de caza: la cetrería y la montería; el resto de técnicas -trampeo, liga, hoyos, pajarería, hurón, etc.tiene una aparición tardía, probablemente debido a que era considerada caza de pobres ${ }^{8}$ o meramente defensiva, aunque tuvieran que participar ocasionalmente los señores 9 .

Van den Abeele, en un pequeño pero informativo cuadro, ha establecido el número mínimo de obras que se produjeron durante el período medieval; el de manuscritos en los que se conservan, en qué lenguas están escritos y cuántos de ellos están ilustrados (Tabla 1) ${ }^{10}$.

\begin{tabular}{|c|c|c|c|c|}
\cline { 2 - 5 } \multicolumn{1}{c|}{} & $\begin{array}{c}\text { Número } \\
\text { de tratados }\end{array}$ & $\begin{array}{c}\text { Período } \\
\text { de redacción }\end{array}$ & $\begin{array}{c}\text { Número de } \\
\text { manuscritos }\end{array}$ & $\begin{array}{c}\text { Manuscritos } \\
\text { ilustrados }\end{array}$ \\
\hline latín & 35 & ss. X-XIV & 75 & $9[+3]$ \\
\hline francés / occitano & 46 & ss. XIII-XV & 181 & $74(+9)$ \\
\hline español / portugués / catalán & 28 & ss. XIII-XV & 63 & 4 \\
\hline italiano & 29 & ss. XIII-XV & 71 & $11(+3)[+8]$ \\
\hline inglés & 10 & s. XV & 46 & 7 \\
\hline alemán & 9 & s. XV & 42 & 3 \\
\hline neederlandés & 2 & s. XV o XVI & 2 & 0 \\
\hline Total & 159 & X a XVI & 480 & $108(+12)[+11]$ \\
\hline
\end{tabular}

Tabla 1. Manuscritos venatorios medievales conservados según van den Abeele ${ }^{11}$

Como puede observarse en la tabla 1, los ámbitos lingüísticos latino y románicos son los que presentan una mayor producción; que la literatura

\footnotetext{
${ }^{7}$ Baudouin van den Abeele, La littérature cynégétique, Turnhout, Brepols, 1996, p. 29.

${ }^{8}$ Baudouin van den Abeele, Texte et image dans les manuscrits de chasse médiévaux, Paris: Bibliotheèque nationale de France, 2013, p. 14.

${ }^{9}$ José Manuel Fradejas Rueda, «El noble exerçiçio de caça y monte», en Estudios mirandeses: Anuario de la Fundación Cultural «Profesor Cantera Burgos», 27:2 (2007), pp. 97-112.

${ }^{10}$ Esta tabla necesita una breve explicación. Se trata de textos redactados hasta el final del siglo xv e incluye copias del quinientos de obras producidas antes de 1500. En la columna de la derecha el número entre paréntesis indica el número de manuscritos que han reservado espacio para incluir las ilustraciones, pero que no llegaron a realizarse; y la cifra entre corchetes indica el número de manuscritos que tienen ilustraciones, pero que no son de tema cinegético; véase van den Abeele, Texte et image dans les manuscrits de chasse médiévaux, p. 16 n. 17.

${ }^{11}$ Ibid., p. 16.
} 
vernácula románica se produce a partir del siglo XIII mientras que el mundo germánico es más tardía así como que la latina es la más longeva ya que abarca cinco de los seis siglos considerados ${ }^{12}$. La última información que presenta la tabla es que una cuarta parte de ellos están ilustrados, pero con una curiosa nota: el ámbito galorrománico es el que más casos presenta. Esto ha hecho ver a van den Abeele que el concepto de libro de caza ilustrado es de origen francés, pero que es relativamente tardío puesto que se inicia con el Livre du Roi Modus et la reine Ratio, escrito por Henri de Ferrières hacia $1350^{13}$. Aunque el primer ejemplo de un texto venatorio ilustrado se halla en el manuscrito Cod. Gr. Z.479 de la Biblioteca Nazionale Marciana, no obstante, hay que excluirlo por no tratarse de una obra venatoria medieval, tan solo copia de un texto clásico.

Sin embargo, hemos de plantearnos qué se ha de entender por manuscrito ilustrado. Aquí seguimos las observaciones de van den Abeele, y solo se han de considerar aquellos manuscritos provistos de una decoración figurativa que responde al texto. Esto excluye, por lo tanto, los numerosos manuscritos que presentan frontispicios decorados, con orlas vegetales o geométricas y heráldicas o numerosas iniciales ornadas, ya sean a tintas o con dorados, pues en estos casos los podemos considerar como meras copias de lujo. Es el primer grupo el que es de interés, pero dentro de él, van den Abeele establece una subdivisión: por una parte, manuscritos ilustrados en sentido estricto y, por la otra, manuscritos que solo presentan un frontiscipio alusivo o una miniatura que anuncia de manera general el tema.

Dentro de los del primer caso, pueden citarse como ejemplos paradigmáticos el ms. Pal. lat. 1071 de la Biblioteca Vaticana que contiene la copia manfrediana del De arte venandi cum avibus de Federico II, o el ms. 10218-19 de la Biblioteca real de Bruselas que atesora una copia de Livres du roi Mo$d u s$ de Henri Ferriéres, ambos con una programa ilustrativo minucioso que ilumina el texto al que acompañan.

${ }^{12}$ Esta es una falsa apreciación, pues algunos de los textos latinos son de origen inglés, como el $D e$ avibus tractatus de Adelardo de Bath (c. 1080 - c. 1150) Adelard of Bath, conversations with his nephew: On the same and the different, Questions on natural science, and On birds, ed. de Charles Burnett, Cambridge, Cambridge University Press, 1998, pp. 238-74, mientras que otros, del ámbito románico, específicamente galorrománico, son producto inglés, como los tratados anglonormandos; véase Tony Hunt, Three Anglo-Norman treatises on falconry, Oxford, Society for the Study of Medieval Languages and Literature, 2009.

${ }^{13}$ van den Abeele, Texte et image dans les manuscrits de chasse médiévaux, pp. 18-19. 


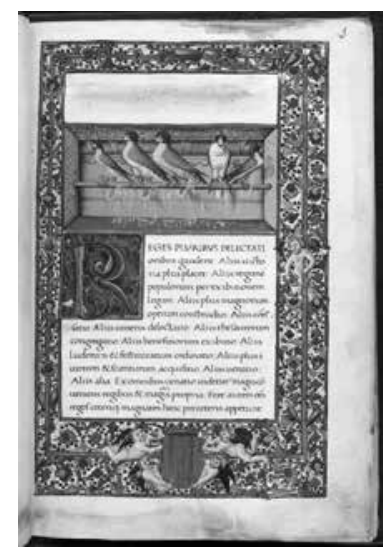

Fig. 1. Frontiscipio del Moamin, New Haven, Beinecke Library, ms. 446

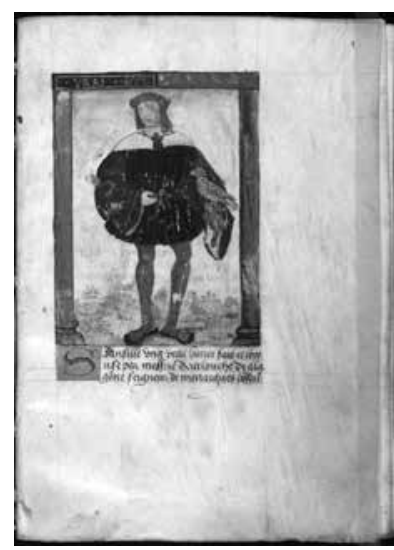

Fig. 2. Frontiscipio Fauconnerie de Arthelouche de Alagona, New Haven, Beinecke Library, ms.162

El segundo modelo lo representa el Moamín de Yale (Beinecke ms. 446), cuyo frontispicio está hermosamente ornado con una orla floral habitada por aves y putti, de los que cuatro de ellos, en el margen inferior sostienen las armas de Alfonso I de Aragón, y en el que el motivo venatorio viene dado por la alcándara en la que están posados cinco halcones perfectamente guarnecidos de caperuzas, cascabeles, pihuelas y lonjas y en la que el detalle minucioso es la representación de las tullidurias de los halcones (figura 1), sin embargo el resto del códice no presenta ninguna otra ilustración referente al tema, salvo las iniciales decoradas. En el mismo caso se encuentra una de las dos copias de la Fauconnerie de Arthelouche de Alagona que posee la Universidad de Yale; una de ellas (Beinecke, ms. 162) presenta en el folio 1r la miniatura de un halconero (figura 2) mientras que en el resto del manuscrito se limita a iniciales decoradas.

Un tercer grupo, no considerado por van den Abeele, lo podrían constituir aquellos manuscritos venatorios que dedican gran parte de su contenido a los aspectos veterinarios y que solo presentan algunas ilustraciones que sirven única y exclusivamente para mostrar cómo se deben de hacer las $\operatorname{cosas}^{14}$. Me

\footnotetext{
${ }^{14}$ En cierta medida podría considerarse el segundo libro De arte venandi cum avibus, pero este, aunque enseña cómo son las lonjas, pihuelas, tornillos y cascabeles (ff. $62 \mathrm{v}-66 \mathrm{v}$ ), cómo poner la caperuza (ff. 105107), asegurar la lonja en las alcándaras y posaderos (ff. 85v-87r), corrección de las debatiduras (f. 86v$87 \mathrm{r}$ ), o cómo sostener el halcón al montar a caballo (ff. 98r-100v), aunque algunas pudieran estar más cerca de los cuidados veterinarios como es el caso del descosido de los ojos (f. 61v) o el corte de uñas (f. 62v). Para el texto del De arte venandi cum avibus en español véase José Manuel Fradejas Rueda, El Arte de la cetrería de Federico II, Ciudad del Vaticano, Testimonio, 2004 y para el texto en latín (con traducción al italiano) Federico Hohenstaufen, De arte venandi cum avibus = l'arte di cacciare con gli uccelli: edizione e traduzione italiana del ms. lat. 717 della Biblioteca Universitaria di Bologna collezionato con il ms. Pal. lat. 1071 della Biblioteca Apostolica Vaticana, ed. de Anna Laura Trombetti Budriessi, Bari, Laterza, 2000.
} 
refiero a casos como la segunda copia de la Fauconnerie de Arthelouche de Alagona de la Beinecke Library (ms. 667, f. 45r) en la que se representa un halcón y todos los puntos en los que se puede dar un cauterio a las aves de cetrería enfermas (figura 3). Es el mismo caso que el del Libro de la caza de las aves de Pero López de Ayala, o el Livro de falcoaria de Pero Menino que solo incorporan una serie de instrumentos quirúrgicos, aunque en un único caso de Ayala (HSA, ms. B2583, f. 1r), que presenta un frontiscipio de lujo (figura 4) como muchos otros códices de otras materias, ofrece una imagen del sujeto principal del tratado: un halcón sentado en su alcándara dentro de un medallón de fondo azul.

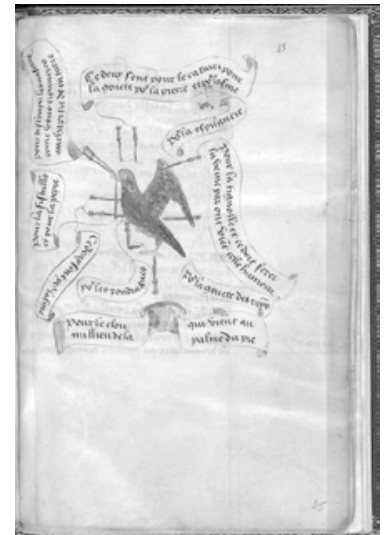

Fig. 3. Artelouche de Alagona, Traité de fauconnerie (New Haven, Beinecke Library, ms. 667). Esquema de los lugares en los que se han de aplicar las cauterizaciones a un halcón.

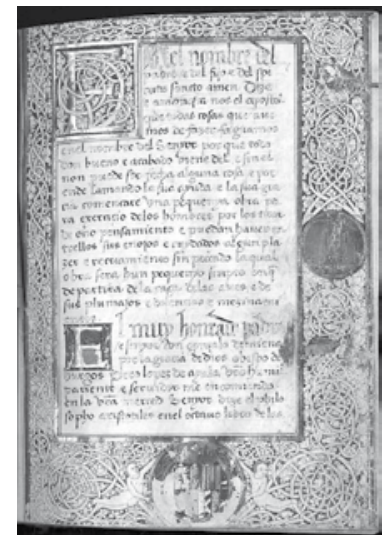

Fig. 4. Pero López de Ayala, Libro de la caza de las aves. Frontispicio. Nueva York, HSA, ms. B-2583.

La tradición venatoria iberorrománica, aunque es rica, 28 tratados conservados en 63 manuscritos, es paupérrima en lo que se refiere a la ilustración de los libros de caza, puesto que en su gran mayoría los textos venatorios hispánicos son textos prácticos, realmente copiados para los cazadores, no para guardarlos en las bibliotecas de los grandes señores, aunque en este aspecto hay notorias excepciones. Sin embargo, la pieza que podría ser la joya de la corona está en paradero desconocido y solo sabemos de ella por las vagas referencias de dos bibliógrafos decimonónicos:

Pedro I de Castilla.- Libro de las cacerias del Rey D. Pedro I.

«El Libro de las Cazerias del Rei D. Pedro, Códice prezioso. (me dize el Dean Zepero, en Sevilla, 7 en $^{\circ}$ 1845) con zerca de 200 iluminaciones, el cual existía en la Biblioteca de los Cartujos de Sevilla, fue vendido a un inglés. De 
consiguiente en Inglaterra debe de parar. N. B. Sigase este libro. La Granja de los Cartujos de Cazalla (dize el mismo que) era la Halconeria del Rey D. Pedro.- Gallardo.»

Hemos copiado esta nota de la misma original del sabio bibliografo D. Bartolomé José Gallardo, que nos la ha mostrado el erudito D. José Sancho Rayón ${ }^{15}$.

y de la que once años después Francisco de Uhagón y Enrique de Leguina se hicieron eco:

Pedro I de Castilla.- Libro de la Cacerías del Rey D. Pedro I

MS. Citado en una nota de Gallardo. Códice precioso, dice, con cerca de 200 iluminaciones, el cual existía en la Biblioteca de los Cartujos de Sevilla y fue vendido a un inglés ${ }^{16}$.

Si se conociera el paradero de este códice podría tenerse una visión maravillosa de la cetrería en la época de Pedro I, rey que aparece constantemente entre las anécdotas de caza del Libro de la caza de las aves de Pero López de Ayala y que, según parece, está figurado, como infante de Castilla, en el Libro de la montería (Madrid, Biblioteca Real, II-2105, f. 37v). Lo más cercano a la información de estos bibliógrafos es el llamado códice de la Cartuja o códice de Palacio (Real Biblioteca, ms. II-2105) del Libro de la montería, aparentemente escrito por el rey Alfonso XI, aunque es una tema ampliamente debatido desde el siglo XIX ${ }^{17}$.

Este códice es el libro de caza escrito en la península Ibérica más rico en lo que respecta a la decoración y que tiene referencia al contenido, aunque no es un códice cuyo plan de iluminación se completara puesto que debería haber contenido catorce miniaturas, pero solo se llegaron a realizar seis (ff. $1 \mathrm{r}, 15 \mathrm{v}$, $34 \mathrm{v}, 83 \mathrm{v}, 91 \mathrm{r}$ y $91 \mathrm{v}$ ) y se dejaron huecos en blanco perfectamente delimitados con filetes de oro para otras ocho (ff. 84r, 93r, 95r, 110r, 112v, 150r, 154v y $175 \mathrm{v})$; en algunos de estos espacios aparecen las expresiones «ystorja de lo de suso» (f. 93r) e «ystorja» (ff. 95r, 114v, 150r, 154v y 175v) ${ }^{18}$. Así mismo, el comienzo de los libros segundo (f. $35 \mathrm{r}$ ) y tercero (f. $45 \mathrm{v}$ ) están adornados

\footnotetext{
${ }^{15}$ José Gutiérrez de la Vega, Bibliografía venatoria española, Madrid, M. Tello, 1877, pp. 9-50.

${ }^{16}$ Francisco Uhagón y Enrique de Leguina, La Caza, Madrid, Ricardo Fé, 1888, p. 60.

${ }^{17}$ José Manuel Fradejas Rueda, «El autor del Libro de la Montería: historia y comentario de seis siglos de controversia», en Actas II Congreso Internacional de la Asociación Hispánica de Literatura Medieval (Segovia, del 5 al 9 de octubre de 1987), Alcalá de Henares, Universidad de Alcalá, 1992, pp. 285-312.

${ }^{18}$ La mejor forma de poder ver las miniaturas del Libro de la montería es por medio del trabajo divulgativo de Matilde López Serrano, Libro de la montería del rey de Castilla Alfonso XI. Estudio preliminar, Madrid, Editorial Patrimonio Nacional, 1969; renunciamos a su inclusión en el presente trabajo debido las altísimas tasas de reproducción que Patrimonio Nacional carga.
} 
con sendas orlas florales, motivo que aparece en todos los folios que contienen o deberían haber contenido una miniatura. La orla puede ser meramente floral con hojas de acanto, flores azules y rosas, y detalles de oro o estar habitada por putti, aves, animales (perro, dragones y jabalíes) y personajes.

La primera gran miniatura, en el folio 1r, se inserta dentro de un gran frontispicio con orla floral en la que habitan varias aves y putti, de los que los dos en el margen inferior sostienen el escudo real de Castilla y León; los tres del margen superior sujetan una banda que debería haber contenido algún lema; y el del margen derecho parece estar dando algo de comer a un dragón. La miniatura por sí sola no parece realmente informativa del contenido del libro ya que presentan al rey sentado en su sitial y cuatro personajes de los que tres de ellos están armados y uno de ellos lleva a la espalda una trompa; entre el rey y el montero del primer plano, lado izquierdo, hay un perro tendido con una gran herida sangrante en la parte superior de la pata delantera derecha. De esos datos se podría inferir el contenido.

La miniatura del folio $15 \mathrm{v}$, que ocupa la mitad superior de un folio enmarcado en una orla floral, representa la caza de un jabalí en la que participan cinco cazadores y nueve perros, de los que cuatro llevan protecciones. Esta escena aparece al comienzo del capítulo en el «que fabla[rá] en que manera deue fazer el montero que quiere fazer buen can de trayella» y al final del que ha tratado «en que manera deuen fazer quando quisieren correr monte de noch» el cual concluye informando de que «[e]sta montería es mejor para puerco que para osso» ${ }^{19}$. No queda claro a cuál de los dos capítulos puede referirse, quizá al que la precede ya que la única pieza mostrada en la miniatura es un jabalí (puerco), y en el cuerpo del capítulo se dice «ayuntense vnos ocho o seys -[monteros]- a lo menos con sus canes», aunque solo se han figurado cinco; pero también podría referirse al capítulo siguiente en el que se menciona un can maestro que es el responsable de levantar el vena$\mathrm{do}^{20}$ (ciervo, jabalí u oso), que es el único que no está retenido por alguno de los monteros, y después deberán soltarse «todos los otros canes que van en aquella busca».

${ }^{19}$ Alfonso, Libro de la montería: based on Escorial MS Y.II.19, ed. de Dennis P. Seniff, Madison, Hispanic Seminary of Medieval Studies, 1983, p. 16.

${ }^{20}$ En el Libro de la montería toda vez que aparece el término venado se refiere a cualquier animal susceptible de ser cazado. En ningún momento se refiere al ciervo. Esta es una extensión del término que se incorpora al léxico español con la llegada de la dinastía de los Austria que preferían la caza de las reses rojas (ciervo, corzos...) a las reses negras (jabalíes, osos), como muestra Sebastián de Covarrubias, Tesoro de la lengua castellana o española según la impresión de 1611, con las adiciones de Benito Remigio Noydens publicadas en la de 1674, Barcelona, Horta, 1943. 
La tercera miniatura (f. $34 \mathrm{v}$ ), a página completa y enmarcada en orla floral, retrata, según López Serrano ${ }^{21}$, al infante don Pedro, futuro Pedro I, sentado en un sitial y rodeado de sus cazadores, de los que tres están sentados en el suelo y sostienen en su regazo un perro herido, quizá muerto, presumiblemente por el jabalí que aparece tendido en primer plano. Al fondo, tras una colina dominada por un frondoso árbol con frutos anarajandos -según López Serrano se trata de un naranjo ${ }^{22}$, pero lo más probable es que se trate de un madroño-, se ven un oso y un ciervo, las otras dos grandes piezas de las que trata el Libro de la montería. Lo más importante de esta miniatura es que se trata de la única a folio completo y se encuentra ubicada al final de la primera parte del segundo libro, es decir, en medio del tratado sobre los perros de caza, lo que no sucede en ningún otra ocasión dentro de esta obra: que haya una miniatura al final de un libro o al comienzo, salvo, claro está, el frontispicio.

La cuarta escena se encuentra en el folio $83 \mathrm{v}$, ya muy alejada de la anterior, pero con la peculiaridad de que este es el primero de los dos casos en el que en el programa iluminador del códice ofrece dos miniaturas consecutivas $\mathrm{y}$, aparentemente, conectadas entre sí, aunque la segunda, en el folio 84r no llegó a realizarse. La miniatura pintada presenta la comida del rey, quien está sentado solo a la mesa mientras que la partida de cazadores o están a su espalda o alejados de la mesa con sendos perros y al fondo, como es usual, se hallan los montes por los que andan trasteando. Las piezas que se muestran son tres osos, un ciervo y el detalle de un conejo, animal del que no trata el Libro de la montería ${ }^{23}$. Otra particularidad de esta escena es que el ciervo y uno de los osos parecen estar encerrados dentro de un cercado.

Sin embargo, lo más curioso es la presencia del espacio para otra miniatura enfrentada y a continuación de la anterior. Además, no hay texto alguno entre la miniatura del folio $83 \mathrm{v}$ y la del $84 \mathrm{r}$, y se da la circunstancia de que se encuentra justo antes de comenzar la larga narración de la persecución de un oso en la zona de El Tiemblo, Navaluenga y Burgohondo, en la vertiente sur de la sierra de Gredos, montería que les llevó cinco días. Posiblemente este hueco se estableciera para representar pictóricamente la narración que comienza justo debajo del espacio en blanco y que se extiende a lo largo de los tres folios siguientes. Sin embargo, es mucho más factible que ambas

\footnotetext{
${ }^{21}$ López Serrano, Libro de la montería del rey de Castilla Alfonso XI. Estudio preliminar, p. 18.

${ }^{22}$ Ibid.

${ }^{23}$ Las únicas ocurrencias de conejo en el Libro de la montería forman parte de elementos toponímicos: «La pared del conejo y arroyo del conejo ... nava el conejo», Alfonso, Libro de la montería..., p. 105.
} 
miniaturas sean la representación gráfica de toda la aventura de esos cinco días, pero se dejó sin representar una parte del lance.

Las miniaturas quinta (f. 91r) y sexta (f. 91v) ilustran una acción de caza que tuvo lugar la zona de Hoz de Escarabajosa ${ }^{24}$ y se sitúan justo al final del relato. En ambas aparece el rey y se representan ciertos personajes menores que se repiten en ambas miniaturas, lo que permite conectar ambas escenas: dos musulmanes a caballo identificables por medio de los turbantes con que se tocan; un personaje negro, a pie y con ropaje de tonos rojizos; dos monteros a caballo que están con el rey en la primera escena, están alejados del rey, pero en la misma posición en la segunda. En ambas miniaturas aparecen dos osos, que es lo que se indica al principio del relato - «soltar a dos ossos» ${ }^{25}-\mathrm{y}$ el aspecto general del paisaje es el mismo. Esta montería les ocupó dos días $-\ll$ Et acesçionos vn lunes soltar y a dos ossos ... Et otro dia, martes, ... et andodieron con el fasta medio dia, et fue a morir»-. La primera escena (f. 91r) resume el primer día de caza, mientras que la segunda (f. 91v), aunque no se ve la captura del oso, figura la acción del martes ya que en ese día mandó que «preguntasen a algunos pastores que ora auian oydo vn can de vnas bozes delgadas», y en el medio plano de la segunda miniatura, en un claro de los montes, se ve un pastor, sentado en el centro y tañendo una gaita, al que acompañan nueve ovejas repartidas en tres grupos.

En el folio 93r hay espacio para una miniatura que no se llegó a trazar, tan solo se realizó la orla floral en cuyo margen inferior se ve a dos personajes. El de la derecha tocando una trompa, mientras que el de la izquierda empuña una azagaya (solo está dibujada) con la que está atacando a un jabalí (de color amarillo) que se encuentra medio escondido tras una hoja de acanto. Bajo el margen de oro superior, que enmarcaría la miniatura, se puede leer «ystorja de lo de suso». La historia a la que se refiere es la de los dos días, domingo y lunes, que emplearon en la caza de un oso en la zona de Cadalso - «et duro esta montería vn dia y vna noche, et otro dia fasta medio dia» ${ }^{26}-$ y porque «fizo buena fazaña este can ... posimos lo en este libro» ${ }^{27}$.

El folio $95 \mathrm{r}$ estaba preparado para recibir una «ystorja» (como en el caso anterior la indicación ha quedado tachada por el marco de oro dentro del que figuraría la ilustración). De nuevo habría sido la representación de una partida de caza, en esta ocasión a orillas del río Alberche. Es la montería que más días duró entre las narradas en el Libro de la montería, puesto que se alargó

\footnotetext{
${ }^{24}$ Ibid., pp. 78-79.

${ }^{25}$ Ibid., p. 78.

${ }^{26}$ Ibid., p. 79.

${ }^{27}$ Ibid.
} 
«desde el lunes fasta el viernes, a ora de medio dia que morio» ${ }^{28}-$. Concluye el relato con «e por tal monteria commo esta dize el enxienplo que "porfia mata venado"». A continuación se encuentra el espacio cuadrangular para la miniatura que narraría pictóricamente la montería. En el margen inferior de la orla floral se encuentran, de izquierda a derecha, un perro (aunque no se asemeja en nada a los sabuesos que se pintan en las miniaturas), un putto y un personaje que parece sujetar un gran pájaro verde. López Serrano afirma que se trata de un halconero con azor en la mano, aunque aclara que el ave «parece un papagayo» ${ }^{29}$. No me puedo manifestar si el ave es un azor o un papagayo, pues las aves que aparecen en las orlas del manuscrito de Palacio son absolutamente inidentificables, pero lo que está claro es que no puede tratarse de un cetrero, pues ninguno osaría agarrar del ala una de sus preciadas aves, además, el motivo cetrero está fuera de lugar dentro del Libro de la montería.

El capítulo XII, que describe «los montes de tierra de Ayllon, et de Sepuluega, et de Riaça, et de termjno de Pedraza», se cierra con el relato de una montería que, porque «fue cosa que por uentura non lo oymos decir a nigun montero que ouiese visto otra tal, posiemos lo en este libro» ${ }^{30}$. Tan increíble les pareció hallar muertos juntos al oso y a un perro, llamado Barbado, que salió tras el rastro del oso y al que debió perseguir durante quince días, que al rey no solo consideró pertinente narrarlo en su tratado de caza, sino que incluso planificó hacerlo pictóricamente, aunque no llegó a realizarse. Aquí, podemos ver una doble forma de no querer ser tomado por chufador, algo que preocupaba sobremanera a don Juan Manuel en su Libro de la caza-«porque non lo tengan por muy chufador», «Pero dize don Johan que en todo quanto á dicho fasta aquí en buena verdat no á dicho chufa ninguna», «Et por[que] en la caça acaesçen cosas muy marabillosas et muy graves de creer, et quando los caçadores las dizen, [dizen] los que lo non son tan caçadores que son chufadores», «Et porque los caçadores an presçio de chufadores» ${ }^{31}-$. El folio de esta miniatura (110r) está enmarcado con una orla floral en la que hay dos dragones, un pájaro inidentificable y un ciervo pastando.

En la descripción de los montes de Cuenca se inserta una pequeña anécdota de una sabuesa llamada Bustera que estaba preñada y a la que le llegó el momento del parto mientras perseguía un ciervo ${ }^{32}$. Fue tan brava que «asy

\footnotetext{
${ }^{28}$ Ibid., p. 81.

${ }^{29}$ López Serrano, Libro de la montería del rey de Castilla Alfonso XI. Estudio preliminar, p. 20.

${ }^{30}$ Alfonso, Libro de la montería..., p. 90.

${ }^{31}$ José Manuel Fradejas Rueda, Don Juan Manuel y el Libro de la caza, Tordesillas, Instituto de Estudios de Iberoamérica y Portugal - Seminario de Filología Medieval, 2001, pp. 171-172 y 202-203.

${ }^{32}$ Alfonso, Libro de la montería... Es de las pocas veces en las que se menciona este animal en el Libro de la montería, al que si bien dedica un capítulo «que fabla de las maneras de la monteria del çieruo» (ibid.,
} 
commo paria vn fijo, tomaua le en la boca et ponía le en vn lugar, et tornaua a ladrar el çieruo». Así actuó la sabuesa mientras que parió cuatro o cinco cachorros. Una vez que el ciervo fue abatido, los monteros no pudieron recogerla, pues se había marchado a buscar sus cachorros. Este extraordinario comportamiento de Bustura no solo se quiso reflejar con un pequeño párrafo, sino que atrajo la imaginación de quien diseñara el programa de iluminación del Libro de la montería y reservó espacio para incluir una miniatura alusiva, pero nunca llegó a realizarse, y hoy solo contamos con la orla floral habitada por un putto y tres aves así como el marco de oro que tacha la inscripción «ystoria» (f. 114v).

El folio 158r presenta el espacio necesario para incluir otra «ystorja» que no fue realizada. En esta ocasión hubiera debido ilustrar una montería que se realizó en tierras de Alcántara en la que estuvieron persiguiendo un oso que, si bien hirieron dos veces durante la primera jornada, no lograron abatirlo hasta el día siguiente - «Assi que duro la monteria deste osso que non murio desd'el lunes ffasta el martes, a ora de biesperas, quel matamos $\rangle^{33}-$.

Al comenzar el capítulo en el que se exponen los montes de Sevilla, Niebla y Gibraleón ${ }^{34}$, se narra otra anécdota en la que tomó parte el rey -«et acaescio Nos vn dia»- que, como de costumbre, les llevó más de un día -«Nos tomo alli la noche ... Et desque amanescio ... fasta el medio dia, que la matamos»-- Finaliza el relato con una conclusión acerca de la necesidad de porfiar con los perros y que los monteros conozcan la tierra y a continuación hay un hueco para representar la «ystorja». Solo existe el filete de oro y la correspondiente orla floral que enmarca todo el folio (154v).

En el folio $175 \mathrm{v}$, cuando describe la comarca de Alcalá la Real ${ }^{35}$, se recuerda una accidentada montería en la que abatieron un jabalí, pero este, a su vez, «mato dos monteros, et dos alanos, et vn azemjla, et firio vn caua1lo». Tal desastre merecía ser presentado pictóricamente, y se dejó hueco para la «ystorja», pero solo resta el marco de oro y la orla floral y la mención

pp. 19-20), es una pieza que tan solo aparece 29 veces (en dos más es un elemento médico y en otras siete forma parte de una denominación toponomástica) frente a 1063 ocurrencias de oso y 1103 de puerco (es decir, jabalí) y ocho de encebro, supuestamente el onagro (Equus hemionus), aunque los arqueozoólogos dudan de su existencia real en la península Ibérica; véase Carlos Nores Quesada y Corina Liesau von Lettow-Vorbeck, «La Zoología Histórica como complemento de la Arqueozoología. El caso de Zebro», en Archaeofauna: International Journal of archaeozoology, 1 (1992), pp. 61-71 y Carlos Nores et al., «The Iberian zebro: what kind of a beast was it?», en Anthropozoologica, 50:1 (2015), pp. 21-32.the names zebro and zebra were given to an enigmatic equid widely reported in the Iberian Peninsula during the Middle Ages. Roughly 150 toponyms deriving from the words zebro/a have been recorded in Iberia starting from the $\mathrm{IX}^{\text {th }}$ century A.D. together with 65 Portuguese Forais and 16 Spanish Fueros (i.e. town laws)».

${ }^{33}$ Alfonso, Libro de la montería ..., p. 114.

${ }^{34}$ Ibíd., pp. 116-121.

${ }^{35}$ Ibid., p. 129. 
«ystorja». En este caso es el único en la que el marco de la miniatura está entre dos pasajes de texto: el de la anécdota y el siguiente.

Dos constantes de todas las miniaturas del Libro de la montería son, la presencia en el plano más alejado, de una fortaleza o una ciudad amurallada, al estilo de las que aparecen en los Livres du roi Modus et la roine Ratio (figura 5). La segunda, que exista o no la miniatura, ese folio siempre está enmarcado con una orla floral, aunque esta no es exclusiva de los folios miniados (finalizada o no la miniatura).

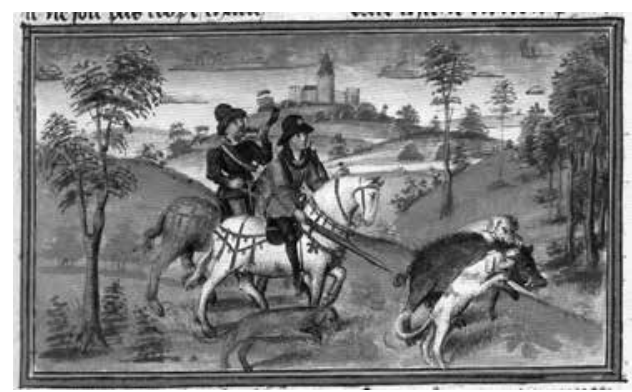

Figura 5. Caza del jabalí. Livres du roi Modus et la roine Ratio. Bruselas, Bibliòtheque Royale, mss. 10218-10219, f. 29r

Exceptuando el frontispicio (f. 1r), la miniatura a folio completo (f. 34v) en la que parece estar representado el infante don Pedro (futuro Pedro I) y en la que los monteros están persiguiendo un jabalí (f. 15v), todas las demás miniaturas que contiene, o que debió de contener en Libro de la montería, manuscrito de Palacio, lo que hacen es representan una serie de anécdotas en las que o bien el rey tomó parte o bien las consideró lo suficientemente extrañas (el sabueso que persiguió un oso y apareció muerto junto a él; la sabuesa que parió mientras cazaba) o desastrosas (muerte de dos monteros) como para recogerlas y reflejarlas en el Libro de la montería, pues hay otras anécdotas que no tuvieron entidad suficiente como para que merecieran una miniatura, como cuando corrieron por primera vez el valle de Vieja, en la sierra de Guadalupe, en la que localizaron «diez osos. Et soltamos a los seys, et murieron los quatro» ${ }^{36}$. Por otra parte, este esquema ilustrativo se concentra en la tercera parte, en la que se describen los montes de los reinos de Castilla y León con minuciosidad ${ }^{37}$.

\footnotetext{
${ }^{36}$ Ibid., p. 105.

${ }^{37}$ Véase José Antonio Valverde, Anotaciones al «Libro de la montería» del rey Alfonso XI, Salamanca, Ediciones Universidad de Salamanca, 2009 y José Manuel Fradejas Rueda, «Los libros de caza medievales y su interés para la historia natural», en Arbor (en prensa).
} 
Este manuscrito es una absoluta rareza dentro de la producción cinegética iberorrománica. Lo más cercano a esto es una de las copias del Libro de la montería que se conservan en la Bibliothèque nationale de France, ms. espagnol 286, que solo contiene los dos primeros libros de los tres que constituyen el tratado, por lo que la posibilidades gráficas disminuyen drásticamente ya que carece de los episodios monteros que fueron dignos de representación pictórica en el ms. de Palacio y se limitan a decoraciones marginales en las que abundan los dragones y los seres fantásticos (ff. 4r, 34r, 48v, 52v, 53r, $53 \mathrm{v}, 56 \mathrm{r}, 56 \mathrm{v}, 58 \mathrm{v}, 60 \mathrm{v}, 63 \mathrm{r}, 64 \mathrm{v})$
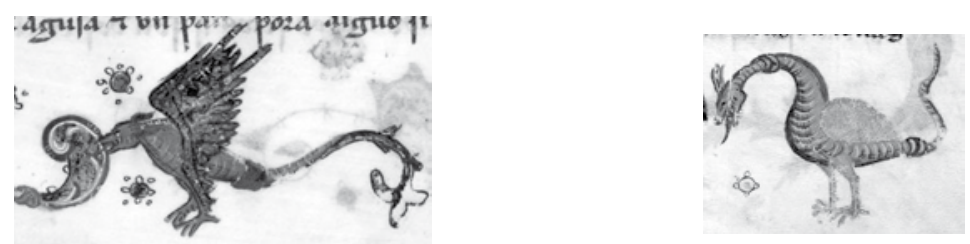

Fig. 6. Dragón, París, BNF, ms. esp. 286, ff. 4r y 34r

normalmente a base de cuerpo de animal y cabeza y torso humano, a veces masculino (ff. 7r, 7v, 12v, 17r, 18r, 19r, 25r, 27r, 29v, 30v, 31r, 32v, 33v, 35r, $37 \mathrm{v}, 39 \mathrm{v}, 41 \mathrm{r}, 42 \mathrm{v}, 43 \mathrm{v}, 44 \mathrm{v}, 45 \mathrm{v}, 47 \mathrm{r}, 48 \mathrm{r}, 49 \mathrm{r}, 54 \mathrm{r}, 55 \mathrm{v}, 57 \mathrm{r}, 57 \mathrm{v}, 58 \mathrm{r}, 59 \mathrm{r}$, $59 \mathrm{v}, 60 \mathrm{r}, 61 \mathrm{r}, 61 \mathrm{v}, 62 \mathrm{r}, 62 \mathrm{v}, 65 \mathrm{r}, 65 \mathrm{v})$
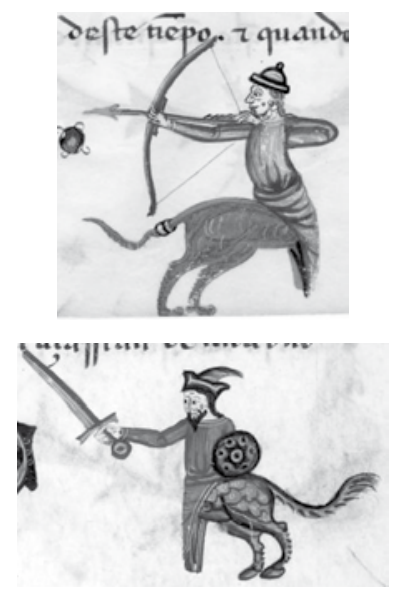

Fig. 7. Monstruos masculinos. París, BNF, ms. esp. 286, ff. 32v, 49r, 59r y 65r
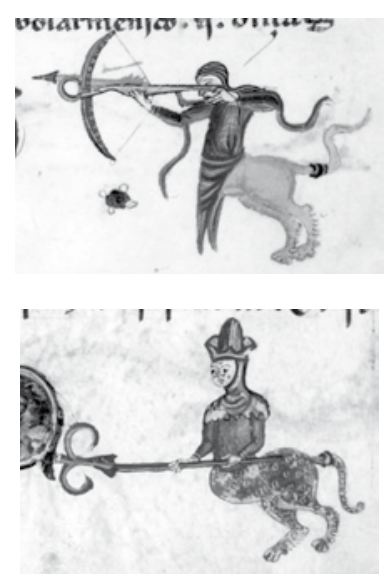

$$
\text { (1) }
$$

a veces femenino (ff. 23v, 28r, 29r, 41v, 45r, 63v-sirena-, 64r) 

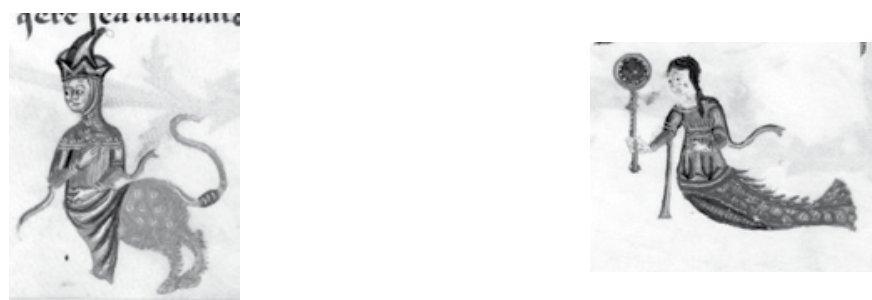

Fig. 8. Monstruos femeninos, París, BNF, ms. esp. 286, ff. 28r y $63 \mathrm{v}$

e incluso hay un monstruo con la cabeza en el pecho (f. 34v) que Seniff cree que puede reflejar la concepción que los europeos tenían de los habitantes de la India debido a la influencia de la Semejança del mundo ${ }^{38}$.

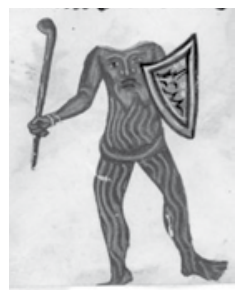

Fig. 9. Monstruo con el rostro en el pecho, París, BNF, ms. esp. 286, f. 34v

Asimismo, presenta algunos animales que nada tienen que ver con la materia del tratado como pavos reales (ff. 17v, 19r, 32r, 42r), patos (ff. 28v, 36r), un calamón (f. 37r), perdices (ff. 2r, 4r), un animal oscuro que podría interpretarse como comadreja (f. 46r) -según parece Seniff lo identifica con un tigre ${ }^{39}-$, un lagarto (f. 46v) y un coleóptero (f. 55r).
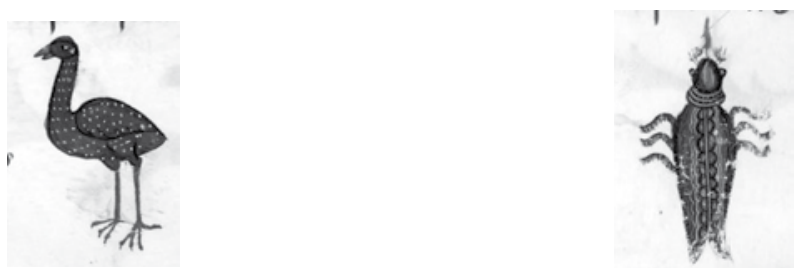

Fig. 10. calamón; París, BNF, ms. esp. 286, f. 37r Fig. 11. coleóptero; París, BNF, ms. esp. 286, f. 55r
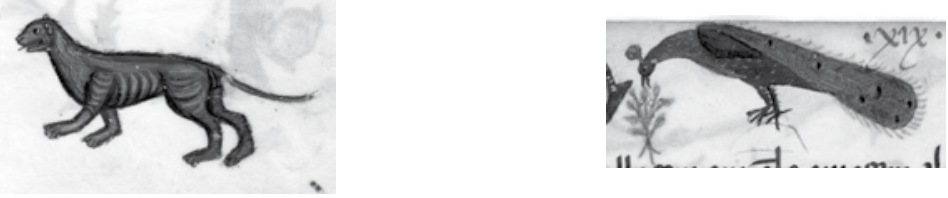

Fig. 12. comadreja; París, BNF, ms. esp. 286, f. 46r Fig. 13. pavo real; París, BNF, ms. esp. 286, f. 19r

${ }^{38}$ Alfonso, Libro de la montería: based on Escorial MS Y.II.19, p. xxx.

${ }^{39}$ Ibid. 
aunque hay detalles monteros a lo largo de todo el códice como osos (ff. 4v, $11 \mathrm{v}, 26 \mathrm{v}$ ), una cabra montesa (f. 17v), jabalíes (ff. 19v, 44r) y un perro bebiendo de una escudilla (f. 43r).

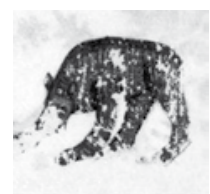

Fig. 14. oso; París, BNF, ms. esp. 286, f. 4v

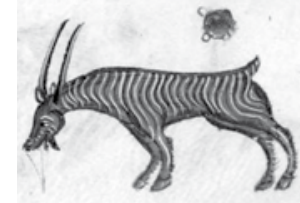

Fig. 16. cabra montesa; París, BNF, ms. esp. 286, f. 17v

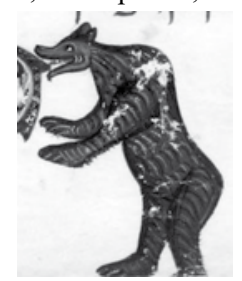

Fig. 18. oso; París, BNF, ms. esp. 286, f. 26v

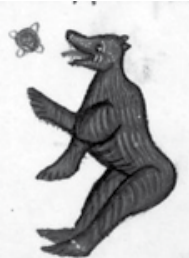

Fig. 15. oso; París, BNF, ms. esp. 286, f. 11r

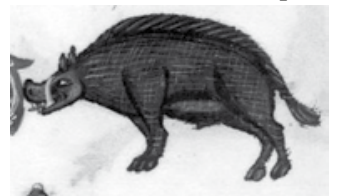

Fig. 17. jabalí; París, BNF, ms. esp. 286, f. 19v

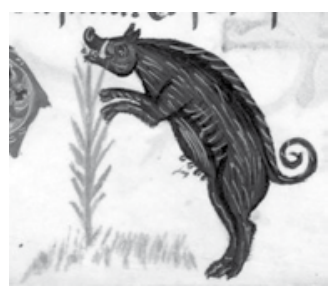

Fig. 19. jabalí; París, BNF, ms. esp. 286, f. 44r

El frontispicio (f. 2r) y el inicio del segundo libro (f. 39v) ofrecen las armas de Aragón. En el primer folio junto con un dragón, y en el margen inferior representa una perdiz y un perro así como el interesante folio orlado

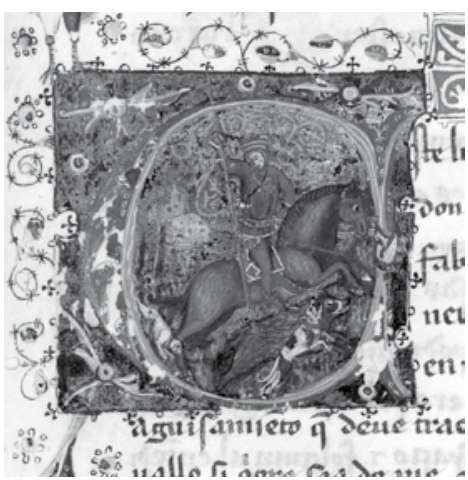

Fig. 20. BNF, esp. 286, f. 4r, detalle

(f. 1r) que incluye las armas de Aragón en los tres márgenes exteriores, un pavo real sobre la inicial historiada, dos medallones en la parte superior, uno con un perro y otro con una perdiz, y dos seres fantásticos en el margen exterior. Sin embargo, lo que cabe destacar en este folio $4 \mathrm{r}$ es la inicial habitada con una detallada escena venatoria en la que un montero a caballo, acompañado por dos sabuesos, alancea un jabalí (figura 20).

En definitiva, un manuscrito ricamente decorado que a duras penas se puede 
considerar un manuscrito de caza iluminado salvo por la inicial y la representación de osos, jabalíes, cabra montesa y perros que figuran en los márgenes.

Los otros dos textos que conforman el canon montero iberorrománico: el Livro da montaria de João I y el Tratado de montería (Londres, British Library, ms. Add. 28709) son incluso más pobres que su antecedente. El Tratado de montería no presenta ilustración alguna y el Livro da montaria tan solo ofrece dos esquemas. Uno sobre la alineación de las pezuñas del jabalí y otro referente a cómo plantear el medio cerco ${ }^{40}$.
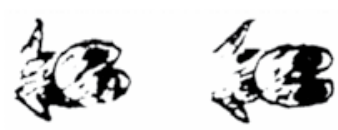

Fig. 21. Rastro del jabalí, Lisboa,

Fundação de Oriente, f. 36v

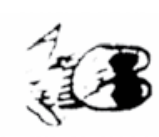

Fig. 22. Medio cerco al jabalí, Lisboa, Fundação de Oriente, f. $71 v$

El gran problema es que para el Livro da montaria tenemos que conformarnos con las copias del XVII y XVIII que se hicieron del original medieval en Monforte de Lemos y que fue destruido, aunque se han recuperado varios folios utilizados como componentes de legajos localizados en el Archivo Histórico Provincial de $\mathrm{Lugo}^{41}$. Estos fragmentos solo hablan de que era un manuscrito de lujo, pero no que estuviera ilustrado. No sabemos, pues no se han dado a conocer aún todos los fragmentos, si los diseños que presentan las copias modernas existen.

\footnotetext{
${ }^{40}$ Para la edición del texto véase la tesis doctoral José María Abalo Buceta, «El Livro da Montaria de D. João I de Portugal (1415-1433)», Universidad de Valladolid. Facultad de Filosofía y Letras, 2009. [En línea]. Enlace: <http://uvadoc.uva.es/handle/10324/127> [Consulta: 26/4/2016].

${ }^{41}$ Una primer fragmento afloró en los archivos de Monforte de Lemos pero fue sustraído y acabó en una colección privada. Véase Ramón Lorenzo Vázquez, «Un fragmento dun manuscrito medieval do Livro da Montaria de D. Joao I de Portugal», en Verba: Anuario galego de filoloxia, 27 (2000), pp. 9-32). Con posterioridad se ha localizado un mayor número de folios; véase José Manuel Fradejas Rueda, «Nuevos fragmentos del Livro da montaria», Crítica Textual para dummies, 17/3/2014. [En línea] <http:// ecdotica.hypotheses.org/740> [Consulta: 26/4/2016]. Para la identificación de quien realizó la copia del manuscrito medieval véase Juan Carlos Conde, «Sobre la identidad del copista del manuscrito del Livro da montaria de João I», en De ninguna cosa es alegre posesión sin compañia: estudios celestinescos y medievales en honor del profesor Joseph Thomas Snow, New York, The Hispanic Seminary of Medieval Studies, 2010, pp. 97-114.
} 
Los textos cetreros iberorrománicos son mucho más pobres aún, pues la iluminación que presentan, como se ha avanzado, son los instrumentos quirúrgicos que ilustran la tradición de textos que se inicia con el Livro de falcoaria de Pero Menino (antes de 1386) y que se difunde por medio del Libro de la caza de las aves de Pero López de Ayala (1386) y sus epígonos: Juan de Sahagún (mediados del siglo Xv) y Juan Vallés (1552). Lo cierto es que la tradición manuscrita de libros de cetrería en castellano se inaugura con la traducción del Kitab al-yawarih o Kitab al-mutawakkil debido a la pluma del cetrero y polígrafo bagdadí Muhammad ibn 'Umar al-Bayzar al-Bagadi y, en especial, por medio del testimonio más antiguo: el manuscrito Reservado 270 de la Biblioteca Nacional de España ${ }^{42}$. Es un rico manuscrito escrito sobre pergamino y con numerosas iniciales decoradas con oro, pero ningún motivo recogido en la decoración de las iniciales hace referencia alguna al contenido, pues aunque algunas son de animales no hacen en verdad referencia al texto, por lo que nos encontramos ante un manuscrito de caza de lujo, pero no iluminado en sentido estricto.

En el Livro de falcoaria de Pero Menino, cuyos manuscritos, como la mayoría de los manuscritos cetreros iberorrománicos, son estéticamente pobres, encontramos los primeros diseños del botiquín de un cetrero ${ }^{43}$. Se trata de varios hierros y un vendaje que se documentan en el ms. 2294 del fondo general
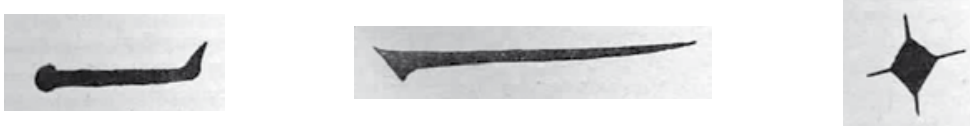

Fig. 23. Instrumentos del Livro de falcoaria, ms. 2294, BNP, extraídos de Lapa ${ }^{44}$

que Pereira recogió al final de su edición en la que atribuía el Livro de falcoaria a Mestre Giraldo ${ }^{45}$ y en el ms. Pombalina 518 de la Biblioteca Nacional de Portugal, la cual carece de los dos primeros del ms. 2294:

\footnotetext{
${ }^{42}$ Muhammad ibn Abdallah Al-Bāzyār, Libro de los animales que cazan = Kitāb al-Ŷawārih , ed. de José Manuel Fradejas Rueda, Madrid, Editorial Casariego, 1987. Para el texto árabe véase Muhammad ibn Abdallah Al-Bāzyār, Das Falken- und Hundebuch des Kalifen al-Mutawakkil: ein arabischer Traktat aus dem 9. Jahrhundert, ed. de Anna Akasoy y Stefan Georges, Berlin, Akademie Verlag, 2005.

${ }^{43}$ Michel Garcia, «La trousse de fauconnier, selon Pero López de Ayala (Castille, xivè siecle», en Chevaux, chiens et faucons. L'art vétérinaire antique et medieval, ed. de A-M Doyen y Baudouin van den Abeele, Louvain-la-Neuve, Université catholique de Louvain Institut d'études médiévales, 2016.

${ }^{44}$ Pero Menino, Livro de falcoaria, ed. de Manuel Rodrigues Lapa Coimbra, Imprensa da Universidade, 1931.

${ }^{45}$ Pero Menino, Mestre Giraldo. Tratado das enfermidades das aves de caça (segundo um manuscrito do seculo XV), ed. de Gabriel Pereira, Lisboa: Officina Typographyca, 1909, p. 26. Véase, sobre esta falsa atribución, Gerardo Pérez, «El cód. 2794 de la Biblioteca Nacional de Portugal y el falso libro de cetrería del Mestre Giraldo: revisitando un problema de atribución», en Cantares de amigos. Estudos en home-
} 

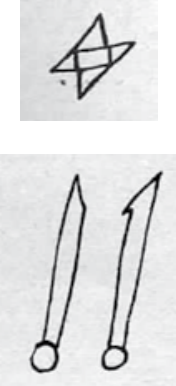
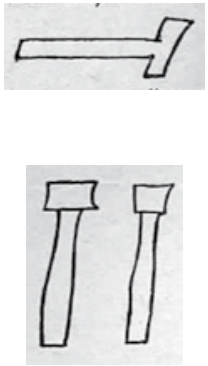
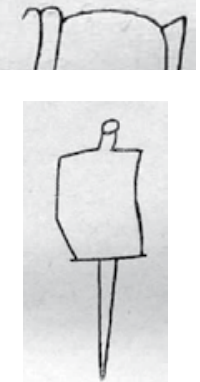

Fig. 24. Instrumentos del Livro da falcoaria según el ms. Pombalina 518, extraídos de Lapa ${ }^{46}$

Desde este momento se difunde por medio del Libro de la caza de las aves de Pero López de Ayala ${ }^{47}$, pero aumenta el número de ilustraciones e incluye cómo cortar las plumas para injertarlas, las agujas para unir los injertos, un dibujo para mostrar cómo es la bolsilla que tiene la bursa pastoris y una cajeta que se hace con barbas de ballena ${ }^{48}$. No todos los manuscritos presentan los diseños, pues en algunos de ellos se omitieron, bien por olvido de los copistas bien, quizá, por que faltaban en el modelo que copiaba.
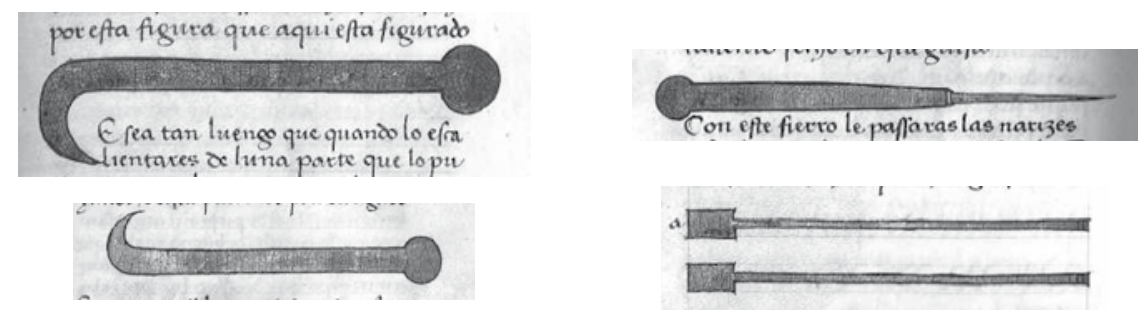

Fig. 25. Hierros en el Libro de la caza de las aves de Pero López de Ayala

naxe a Mercedes Brea, Santiago de Compostela, Universidad, 2016.

${ }^{46}$ Menino, Livro de falcoaria.

${ }^{47}$ Pero López de Ayala, Libro de la caza de las aves, ed. de José Fradejas Lebrero y José Manuel Fradejas Rueda, Barcelona, Castalia, 2016.

${ }^{48}$ Marinela Garcia-Sempere, «"Segons lo caçador conexerà que u ha mester lo ocell”: Sobre el tractat de falconeria anòmim Libre de caça, i el Libro de la caza de las aves de Pero López de Ayala», en Llengua \& Literatura, 24 (2014), pp. 7-32, ha utilizado estas ilustraciones para establecer la relación que existe entre el Libre de caça catalán y el Livro de falcoaria de Pero Menino y el Libro de la caza de las aves de Pero López de Ayala. Para la edición del texto catalán véase Marinela García Sempere, El «Libre de caça»: estudi i edició d'un tractat de falconeria medieval, Alacant, Barcelona, Institut Interuniversitari de Filologia Valenciana - Publicacions de l'Abadia de Montserrat, 2013. 


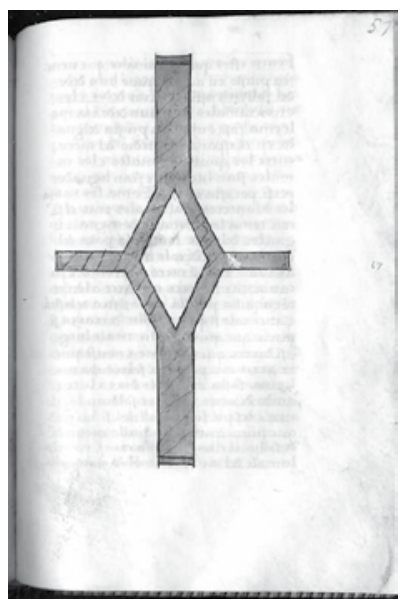

Fig. 26. Vendaje en el Libro de la caza de las aves

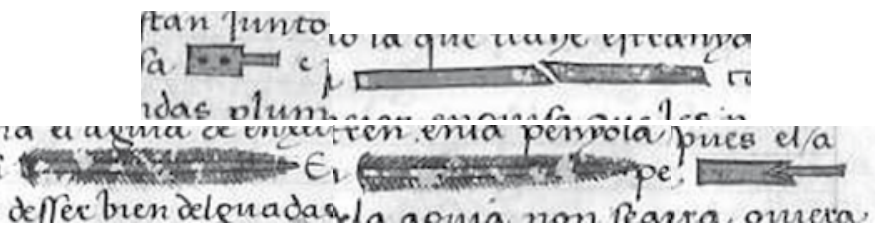

Fig. 28. Cortes de pluma y agujas para el injerto en el Libro de la caza de las aves

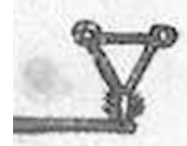

Fig. 27. Bolsilla de la bursa pastoris en el Libro de la caza de las aves

Hubo algún manuscrito que agrupó la mayoría de los instrumentos en un mismo folio (BNE, 2022, ff. 32r-32v; figura 30) o como puede verse al final de la traducción que Gonzalo Rodríguez de $\operatorname{Escobar}^{49}$, en la porción del manuscrito que sigue siendo propiedad de Patrimonio Nacional, Madrid, Biblioteca Real, ms. II-1370, f. 5v; figura 31), lo que no obsta para que algunos de ellos sigan figurando en los lugares correspondientes.

Esta tradición se alargará hasta el siglo XVI, pues en las obras de Juan se Sahagún (siglo Xv), Juan Vallés (1556) y de Fadrique de Zúñiga y Sotomayor (1565), incluirán como únicas ilustraciones alguno de estos elementos, incluso refinándolos como es el caso de las plumas, un posadero y una prótesis para las uñas en el Libro de acetrería y montería de Juan Vallés (imágenes $32-35)^{50}$.

\footnotetext{
${ }^{49}$ José Manuel Fradejas Rueda, «La versión castellana del Livro de falcoaria de Pedro Menino de Gonzalo Rodríguez de Escobar», en Incipit, 30 (2010), pp. 49-109.

${ }^{50}$ Para una edición del texto véase Juan Vallés, Libro de acetrería y montería, ed. de José Manuel Fradejas Rueda, Madrid, Círculo de Bibliofilia Venatoria, 1994.
} 

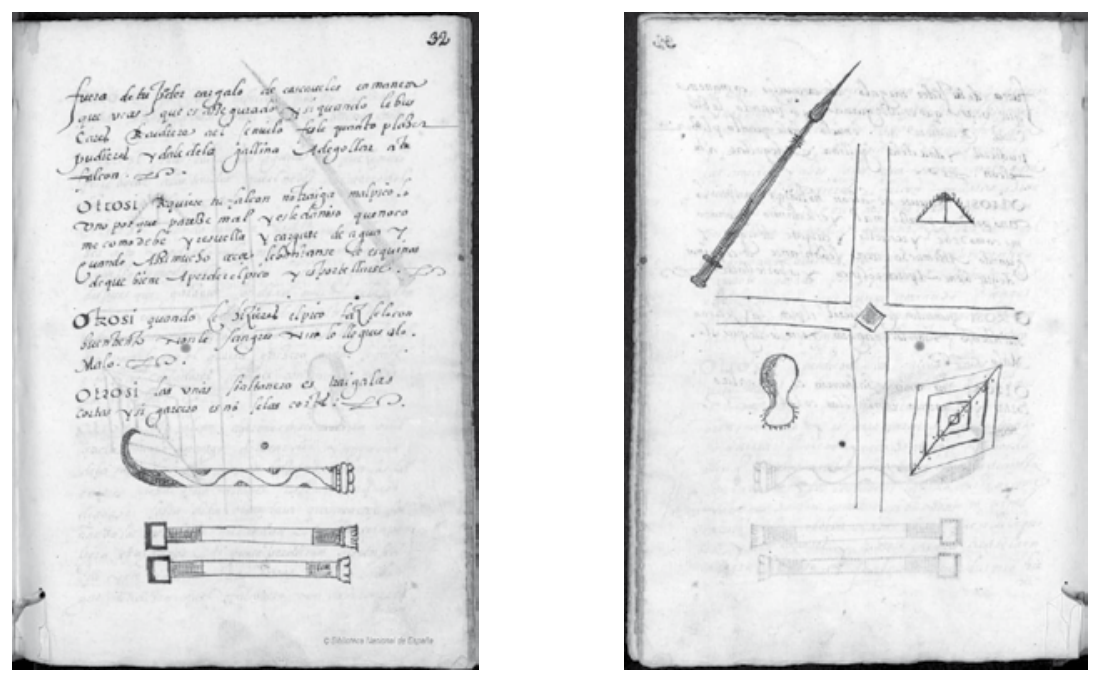

Fig. 30. Algunos de los instrumentos del Libro de la caza de las aves según el ms. 2022 de la BNE, f. 32r-v

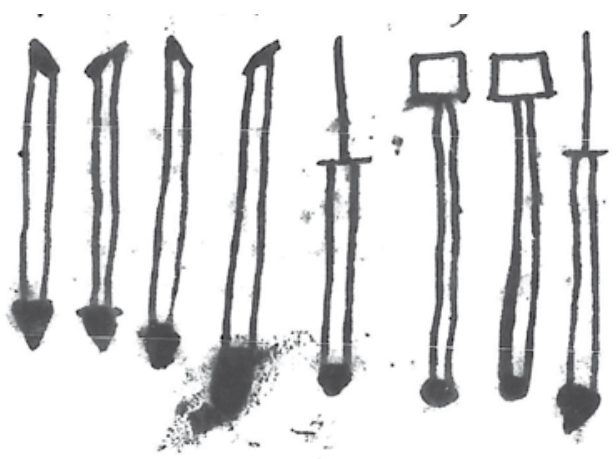

Fig. 31. Algunos de los instrumentos recopilados al final de la versión del Livro de falcoaria de Pero Menino traducido por Gonzalo Rodríguez de Escobar, Madrid, BPR, ms. II-1370, f. 32r-v.

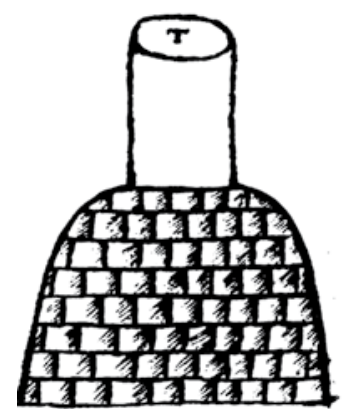

Fig. 32. Posadero para azores, Libro de acetrería y montería, BNE, ms. 3382, f. $34 \mathrm{r}$ 
Fig. 33. Hierros, Libro de acetrería y montería, BNE, ms. 3382, ff. 99r, 101r, 156r

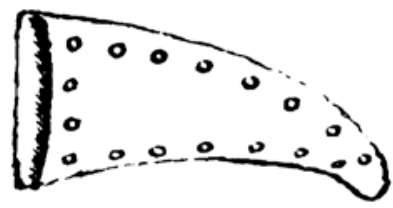

Fig. 34. Dedal, Libro de acetrería y montería, BNE, ms. 3382, f. 162v

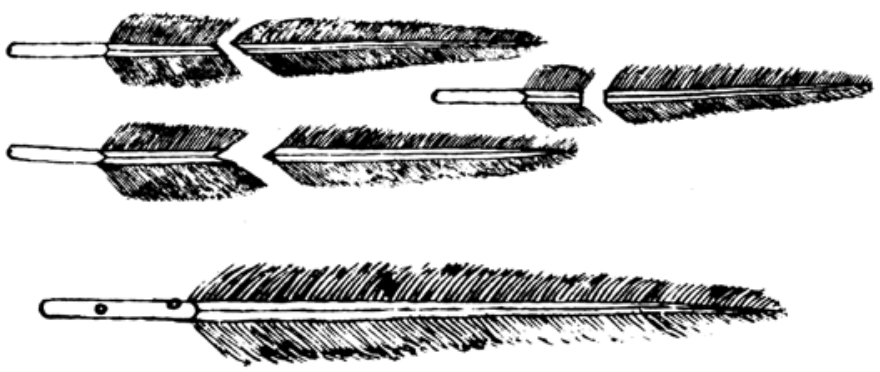

Fig. 35. Injerto de plumas, Libro de acetrería y montería, BNE, ms. 3382, f. 169r-v

Sin embargo, la caza en donde mejor está representada en el mundo iberorrománico, aunque tampoco con grandes muestras, es fuera de los tratados venatorios. Por lo general son pequeñas ilustraciones tópicas como la aparición de un cetrero en el mes de mayo de algunos libros de horas como el de Isabel I de Castilla, Madrid, Palacio Real, ms. II-Tesoro, f. 5v) o de Juana la Loca (Londres, British Library, ms. Add. 35313, f. 3v) o el rey cetrero, que porta un azor -según el texto- y lleva una alano atraillado y sujeto al cinto que aparece en el manuscrito parisino de El caballero Zifar (París, BNF, ms. esp. 36, f. 176v). A pesar de estar parquedad, tenemos una muestra relativamente primitiva, en el sentido de que son las más antiguas, y se hallan en las Cantigas de Santa Maria: dos de ellas están ilustradas con una serie de viñetas que narran pictóricamente los milagros correspondientes (El Escorial, ms. T.I.1), la tercera no es realmente venatoria, pues solo utiliza la caza del oso como representación de un tentación peligrosa ${ }^{51}$.

\footnotetext{
${ }^{51}$ Como en el caso del Libro de la montería de la Real Biblioteca (véase nota 18), renunciamos a in-
} 
La primera corresponde a la cantiga 44 «Esta é como o cavaleiro que perdera séu açor foi-o pedir a Santa María de Salas; e estando na eigreja posoulle na mão». En ella se narra la desgracia de un infanzón aragonés que «foi a caça \& lançou o açor a as perdizes», lo que se muestra en la primera viñeta y a continuación se le ve buscándolo con la ayuda de otro personaje porque «non o podia achar» (viñeta 2). Estas dos primeras viñetas son veraces desde el punto de vista cetrero. En la primera se ve al infanzón a lomos de su cabalgadura, acompañado por dos perros, con el guante en la mano para animar a su azor que vuela tras dos perdices. En la parte inferior se ve a un conejo agazapado. En la segunda viñeta encontramos al infanzón trasteando por el bosque con la ayuda de un ojeador, el guante enfundado. Las dos perdices tranquilamente posadas en el suelo y el conejo (ahora una liebre) agazapado en su cama, pero ofrece un toque de fino humor: hay un tercer perro que ha capturado una liebre (por las largas orejas) y la tiene trabada en la boca. El resto de los paneles cuentan que mandó pregonar la pérdida y cómo no lo halló llevó un exvoto de cera a Santa María Salas, y muestran que mientras que está en la iglesia recupera el azor.

El segundo caso es el de la cantiga 142: «Como el rey don Alffonso lançou un falcon a hũa garça». Esta es, sin duda, la más dramática de todas, pues el milagro evita la muerte por ahogamiento de un hombre de Guadalajara que se presenta voluntario para recuperar la garza que el poderoso halcón del rey Alfonso ha derribado, pero que ha caído en el agua y los perros no pueden recoger a causa de la fortísimas corriente del río Henares. La fuerza del agua lo sumerge dos o tres veces, y todos, salvo el rey, lo creen muerto, pero Alfonso $\mathrm{X}$ confía en que la Virgen lo salvará. Dejando a un lado el pequeño desorden de los paneles cinco y seis, que están invertidos, los detalles cetreros de las demás miniaturas son excelentes. En la primera, la partida de caza está compuesta por el rey y cuatro cazadores más, de los que tres tienen en el puño un halcón, que vemos de espaldas, con caparuzas rojas y el detalle de que las puntas de las alas se cruzan en la espalda de los halcones; el halcón del rey está montando y le ayudan los gritos y el agitar de los guantes. La segunda miniatura sintetiza toda la acción de caza: la garza remonta; se precipita tras ser golpeada por el halcón y romperle el ala, y cae al río («Como o falcon firiu a garça $\&$ broulla a aa $\&$ ca en agua a garça no rio»). En el tercer panel, en el que rey «meneçou a dizer a uozes quen entrara pola garça», el grupo de cazadores ha aumentado: son ocho a caballo, más el rey, más dos peones, uno de ellos debe ser el hombre de Guadalajara que entró en el río, y entre las patas

cluir las imágenes de las Cantigas de Santa María de El Escorial por los mismos motivos. Por otra parte, cualquier lector puede acceder a ellas en multitud de publicaciones y en internet. 
de los caballos y las piernas de los peones hay dos perros, que volveremos a ver asomados al río en la siguiente miniatura. El número de halcones en el puño sigue siendo de tres, todos ellos encaperuzados (el del rey se presume en el aire a la espera de que se recupere la garza aguada); dos de frente y otro de espaldas: el esquema de colores de las aves corresponden al baharí (Falco peregrinus brookei), la variedad residente en la península Ibérica. La penúltima que, como se ha indicado debería ser la última, «Como deu a garça al Rey, $\&$ el Rey \& todos loaron muyto Santa Maria», pero ahora hay cuatro perros sentados que miran hacia el rey; siete cazadores a caballo, incluido el rey, y el peón que entrega la garza captura y recuperada. En esta escena ya solo hay dos halcones, de espaldas y encaperuzados, en la mano de los cazadores. Es una escena absolutamente realística y detallada.

La tercera escena venatoria dentro de las miniaturas de las cantigas de Santa Maria se halla en la cantiga 67 «Como Santa María fez connocer ao óme bõo que tragía o démo consigo por servente; e quiséra-o matar, senôn pola oraçôn que dizía». En el panel se ve a un caballero alanceando un oso. Esta miniatura narra pictóricamente dos acciones por medio de las cuales el demonio «muitas artes buscava per que o algur matasse | per que ouvéss' el a alma» : la caza del oso y la pesca en el mar con el objeto de que el caballero, muy piadoso y limosnero, perezca en un accidente que el mismo diablo trata de provocar ya que incita al oso y menea la barca para que zozobre. Gonzalo Menéndez Pidal identifica esta escena con el pie de imagen «El demonio de la caza» ${ }^{52}$, pues es Satán quien «lle fazía amẽude que caçasse | enas montannas mui fórtes, e eno mar que pescasse $\rangle^{53}$.

La conclusión que se puede extraer es que los manuscritos venatorios iberorrománicos eran básicamente escritos prácticos para un público practicante de dos técnicas venatorias básicas: la montería y la cetrería, aunque las ilustraciones que acompañan los tratados de cetrería no se refieren en ningún momento a las técnicas venatorias sino a instrumentos médicos trazados esquemáticamente, aunque ocasionalmente se enriquecieran (Nueva York, Hispanic Society of America, ms. B2583; Madrid, BNE, ms. 1227, f. $15 \mathrm{v})$ y se pintaran con pan de oro. El llamado manuscrito de Palacio del

${ }^{52}$ Gonzalo Menéndez Pidal, La España del siglo XIII leída en imágenes, Madrid, Real Academia de la Historia, 1986, p. 233.

${ }^{53}$ Las obras alfonsíes ofrecen otra imagen cetrera, en el Libro de los juegos: acedrex, dados e tablas (El Escorial, ms.) hay dos caballeros cristianos jugando al ajedrez y por encima de ellos hay dos halcones, uno de frente y otro de espaldas, posados en la alcándara, a la que están atados por medio de las lonjas y sobre la percha descansan dos lúas. La forma más sencilla de acceder a la imagen es por medio de Alfonso X el Sabio, Libro de los juegos: acedrex, dados e tablas. Ordenamiento de las tafurerías, ed. de Raúl Orellana Calderón, Madrid, Biblioteca Castro, 2007, p. 125. 
Libro de la montería es la gran excepción de los tratados de caza españoles, pues presenta un interesante programa ilustrativo, aunque no se concluyó ya que más de la mitad de la miniaturas no se llegaron a realizar. Por otra parte, son únicas dentro del panorama de los libros de caza ilustrados por cuanto no son imágenes para ilustrar la doctrina, como sucede en los tratados franceses como el Livre du Roi Modus et la roine Ratio de Henri de Ferrières o el Livre de la chasse de Gastón Febus, sino que en el caso castellano narran anécdotas venatorias insertadas en el texto.

Recibido: 26/04/2016

Aceptado: 16/06/2016 


\section{ILUMINAR LA CAZA EN LA EDAD MEDIA: \\ APROXIMACIÓN A LA ICONOGRAFÍA VENATORIA MEDIEVAL IBERORROMÁNICA}

RESUMEN: Desde el arte rupestre la caza ha sido uno de los temas predilectos. Durante la Edad Media surgen los libros de caza, aunque tienen un tenue antecedente en la antigüedad greco-latina, una literatura técnica y práctica que en su momento de apogeo desarrolla un interesante esquema iluminador. Aunque la península Ibérica que presenta una literatura venatoria muy característica llena de notas personales y aspectos exclusivos como la geografía de la caza, sin embargo es paupérrima a la hora de ilustrar los textos puesto que básicamente es una literatura técnica que se limita a presentar los instrumentos necesarios, no obstante hay algunos ejemplos muy interesantes, aunque las mejores imágenes de la caza no ilustran los libros técnicos sino otro tipos literarios. Tras una visión de la historia de la representación de la caza y de los libros de caza ilustrados, se analizan las miniaturas del Libro de la montería y se establece cuál es el significado y función de cada una de ellas. Posteriormente se estudian los instrumentos médico-quirúrgicos mostrados en los libros de cetrería, especialmente en la serie iniciada por el Livro da falcoaria de Pero Menino y difundida por el Libro de la caza de las aves de López de Ayala. Se cierra con un análisis de las miniaturas venatorias de las Cantigas de Santa María.

Palabras Clave: Miniaturas. Caza. Cetrería. Manuscritos iluminados. Edad Media. Renacimiento.

\section{Iluminating the Hunt in the Middle Ages: an ApProach to the Ibero-romance Medieval Hunting ICONOGRAPHY}

ABSTRACT: From the age of Rock art, hunting has been one of the favourite themes. During the Middle Ages hunting books emerge, although they have a tenuous history in the Greco-Latin Antiquity, an interesting technical and practical literature that in its heyday develops an interesting illustrative scheme. Notwithstanding the Iberian Peninsula has a very characteristic hunting literature full of personal notes and has some exclusive peculiarities as guides to the best hunting locations, however it is very poor when it comes to illustrate the texts. Since it is basically a technical literature, it limits its illustrative scheme to represent the necessary tools. However, there are some fine examples, although the best images of the hunt do not illustrate technical books but other literary types. Afterwards, medical and surgical instruments depicted in falconry books, especially in the series initiated by Pero Menino's Livro da falcoaria and disseminated by López de Ayala's Libro de la caza de las aves, will be dealt with. The study closes with an analysis of the hunting miniatures from the Cantigas de Santa Maria.

KeYwords: Miniatures. Hunting. Falconry. Illuminated manuscripts. Middle Ages. Renaisance. 